\title{
Assessment of the quality of hospital hygiene at Gaweye District hospital in Niamey in 2018
}

\author{
Comlan Cyriaque DEGBEY ${ }^{1,2^{*}}$, Mahamadou Seyni YANSAMBOU ${ }^{3}$, Ghislain $\mathrm{SOPOH}^{1}$, \\ Mariama Halirou AMADOU ${ }^{4}$ and Edgard-Marius D. OUENDO ${ }^{1}$ \\ ${ }^{I}$ Regional Institute of Public Health, University of Abomey-Calavi, Ouidah, Benin. \\ ${ }^{2}$ University Clinic of Hospital Hygiene, Hubert Koutoukou National University Hospital Center, Cotonou, \\ Benin. \\ ${ }^{3}$ Central Livestock Laboratory (LABOCEL), Niamey, Niger. \\ ${ }^{4}$ Institut of Pratical Public Health of Niamey, Niger. \\ *Corresponding author; E-mail: comlancy@yahoo.fr; Tel: 0022995960541
}

\begin{abstract}
Nowadays, infections linked to health care and services constitute a great issue of public health. Such a challenge has, not only, contributed to the implementation of structure and, but also, to the increase of the culture of quality and security in health centers. In Niger, this aspect is less explored and documented. The present study aimed at evaluating the quality of hospital hygiene at the hospital of Gaweye district (Niamey) in 2018. This is a cross-sectional, descriptive, and evaluative study of the quality assessment of hospital hygiene at the Gaweye District Hospital. The components under study were: "structure", "Process", and "results". These consist of subcomponents which, in turn, are filled with variables. Ratings were based on standard thresholds (insufficient: $<60 \%$, moderate: [60\% - 80\%], and good: $\geq 80 \%$ ). The results show (i) insufficient availability and accessibility of inputs (structure) with a $25 \%$ quality rating, (ii) an inadequacy in the process with a score of $41.8 \%$, which highlight the non-observance of hospital hygiene barriers; (iii) a deficiency in the results which showed the non-compliance of the barriers to the standards and an insufficient quality of hospital hygiene. Significant discrepancies imply a deficiency in the quality of hospital hygiene at the Niamey Gaweye District Hospital in 2018. It is, therefore, important to take these differences into account and correct them in order to improve the quality of services provided at the Gaweye District Hospital in Niamey.

(C) 2019 International Formulae Group. All rights reserved.
\end{abstract}

Keywords: Evaluation, quality, hospital hygiene, infections linked to health care, Niger.

\section{INTRODUCTION}

Hospital hygiene is a very vast subject. Concerning Public Health, hygiene is at the heart of the daily operation of hospitals. It plays a crucial role in the safety of health staff, patients and their surroundings, and the performance of the health system. In addition, it guarantees the quality of benefits in a health facility suggests that the hospital is not a risk environment for its different users and populations, as well. The failure or absence of this sector leads to the emergence of nosocomial infections (NIA) more widely today, the infections associated with care and services (IAS) that complicate the state of health of patients (Geberemariyam et al. 2018, Zhou et al., 2014). In developed countries, nosocomial infections affect $5 \%$ to $15 \%$ of patients hospitalized in regular services and up to $50 \%$ or more of patients in intensive care units (Nejad et al., 2011). In the United States and Europe, the prevalence of IAS is 
6\% in acute care hospitals and almost $19.5 \%$ in intensive care units (Geberemariyam et al., 2018). As for developing countries, the magnitude of the problem remains underestimated or even unknown, largely because the diagnosis of nosocomial infections is complex and surveillance activities to guide interventions require expertise and resources (Nejad et al ., 2011). Available data show an incidence of nosocomial infections in sub-Saharan Africa ranging from $2 \%$ to $49 \%$, with a higher rate ranging from $21.2 \%$ to $35.6 \%$ among Intensive Care Units (ICU) patients (Mbim et al., 2016). ). In Africa, the prevalence of careassociated infections reached $25 \%$ of hospitalized patients (Nouetchognou et al., 2016). In Benin, the results of the national survey conducted in 2012 reported that the average prevalence of nosocomial infections was $19.1 \%$, of which Surgical Site Infections (SSI) accounted for 24.7\% (Ahoyo et al., 2012). Studies carried out at the CNHU-HKM on the prevalence of ISO in visceral surgery services A and B and on the quality of medical-technical equipment used in operating rooms for the prevention of IAS have respectively revealed nosocomial infection rates. $6.3 \%$ and $6.17 \%$ (Mehinto et al., 2014, Degbey et al., 2013).

A prevalence survey carried out by the World Health Organization (WHO) in 2009 estimated that 1.4 million people got sick in the world as a result of hospital-acquired infections. The highest prevalence is noted in Africa and some developing countries (WHO 2009).

These figures reveal the magnitude and severity of the public health problem represented by NFIs. The main cause of this problem is the lack of awareness pertaining to the importance and practice of hospital hygiene. The study conducted by Iliyasu et al in 2016, show the impact of hospital hygiene training and the application of simple hygiene measures such as hands washing or standard precautions on the quality of care and the decline in IN case.

A study at the Regional Hospital Center (CHR) in Tahoua, Niger, for a period of four months (from June to September 2008), revealed a greater number of nosocomial infections with a rate of $30.89 \%$ on patients aged 56 and over, with an average length of stay of 4 days (Djibo et al., 2013).

The quality of care and services inevitably passes through good hygiene. The problem of hygiene concerns all the questions raised by the implementation and practice of barriers in hospital hygiene. These barriers or set of practices and measures are made available to health personnel in order to prevent hospital infections and to improve the quality of care and services in sanitary structures. Thus, the insufficiency of the quality of hospital hygiene remains the major cause of nosocomial infections and the infections associated to the care in the world. These infections, both in developing and developed countries, are health-related risks and are generally a constant concern in hospital practice and care. They constitute a major cause of complications of health care, leading to an increase in mortality, morbidity and catastrophic expenses (major increase in health costs) through a prolonged hospitalization.

In Niger, there is no national policy for hospital hygiene. This aspect is less explored. This was the case of Gaweye District Hospital in Niamey, where there is no documentation on the prevalence of nosocomial infections and infections associated with care. Nevertheless, the hygiene and sanitation department tries to manage the issue of hospital hygiene through the training of maintenance staff in waste management. Due to the fact that no focus has been on other barriers in hospital hygiene, it is necessary to take stock of the quality of hospital hygiene at the level of this health facility. Thus, the study hypothesis is: the respect of the implementation and the practice of the barriers in hospital hygiene would improve the quality of the care and services at the Gaweye district hospital (Niamey-Niger) in 2018.

The main objective of this study is to evaluate the quality of hospital hygiene at the Gaweye District Hospital in Niamey in 2018.

\section{MATERIAL AND METHODS Framework of the study}

District Gaweye Hospital provided the framework for this study. It is the only district hospital in the Niamey region (Niger), located 
at Gaweye in $5^{\text {th }}$ administrative district of Niamey. Being a reference center for eleven (11) Integrated Health Centers (CSI) and two (2) small clinics, it has a capacity of 54 beds with 99 nursing staff members and 32 for maintenance staff.

\section{Study methods \\ Type of study}

This is a transversal, descriptive and evaluative study on the quality of hospital hygiene at Gaweye District Hospital in Niamey.

\section{Study population}

The study population was made of health care workers, maintenance staff, service managers (in charge of Human Resources, Hygiene and Sanitation), medical equipment (operating tables, table and toolbox for dressing, an incubator), equipments (patient beds), surfaces (room floors) and indoor air. People who did not consent to participate in the study and materials of prohibited areas by health authorities were not included.

\section{Sampling}

The selection has been done through the convenience technique to caregivers, maintenance staff, and patients. It has also been done through the census of service managers (human resources, hygiene and sanitation, chief medical officer) and of medical equipment (operating table, dressing table, tool box, delivery tables and the incubator) as well as simple random sampling technique for patient beds and room floors. It can be retained that 25 respondents were surveyed for the medical staff, 24 were interviewed for patients, 18 were interviewed for maintenance staff, 14 floors were swabbed, 12 bed were swabbed, 2 delivery table were swabbed, one (1) operating table, one (1) dressing table, one (1) tool box and one (1) incubator (swabbed for microbiological analysis). Petri dishes (containing BHI and PCA media) have been placed in 13 rooms for 30 minutes to reveal air contamination.

\section{Data collection techniques and tools}

Four types of techniques were used: (1) direct observation of the hospital environment, (2) questionnaires to nursing staff, patients and maintenance staff, (3) interviews with the personnel managers and (4) the swabbing of materials from the hospital environment that are subject to microbiological analysis.

\section{Variables}

The components under study were: "structure", "process" and "results". These components consisted of subcomponents, which in turn were filled with variables.

"Structure" concerns the hospital hygiene service, hygiene management tools (protocols and standards), human resources, financial resources and material resources (as subcomponents). 32 criteria were gathered to determine the quality of this component.

"Process" includes the subcomponents: hand hygiene and asepsis and antisepsis, biomedical waste management, disinfection and sterilization, and the hospital environment. 43 criteria were used to determine the quality of this component.

"Results" takes into account the respect of the barriers (structure-process) and the contamination of the hospital environment. 120 criteria were evaluated to determine the overall quality of hospital hygiene.

\section{Statistical analysis}

Data entry after cleaning and coding had been performed with the STATA 11.0 software. On a descriptive level, a score 0 or 1 has been assigned to each criterion of each subcomponent variable which defines the level of compliance or not. Analytically, the total scores have served as a basis for assessing each explanatory sub-component. The ratio between the number of "yes" criteria observed and the total number of "yes" criteria expected to assess the score of each subcomponent, on the one hand, and the total scores calculated for all sub-components as well as for all components, on the other hand, allowed to define the level of quality of hospital hygiene. The quality of management was appreciated according to varkevisser's principle: - Good if the score was between $80 \%$ and $100 \%$; - average if the score was between $60 \%$ and $80 \%$; and - Insufficient if 
the score was from 0 to $60 \%$ (Varkevisser et al., 1993).

Qualitative data were subject to content analysis. The swabs were analyzed with specific media (rapid E. coli agar, MuellerHinton broth, Salmonella Shigela agar (SS), Baird-Parker agar (BP), Chapman agar). The rating for the risk levels is: 0 if microbiological count were greater than 100 colonies forming units (CFU) and 1 if it were less than 100 colonies forming units. The score of the subcomponent was obtained by numbering averages less than 100 UFC on the expected total scores.

\section{RESULTS}

\section{Target characteristics}

The targeted population of the study was caregivers and maintenance staff. The caregivers interviewed were 25 agents, with an average age of 40 years (more or less 7 years). This staff had an average service life of 15 years (more or less 8 years) and was predominantly female. The maintenance staff had a median age of 38 years, an average seniority of 9 years (more or less 8 years) and was predominantly female (14/18). Of the 24 patients surveyed, 21 were women with middle age of 35 years old (more or less 16 years old). The average hospitalization duration was 4 days. Patients were aware of the dangers of poor hygiene at a ratio of 20/24. Regarding hand hygiene, 13 out of 24 patients did not wash their hands before going to the toilet and 14 of them did not wash after the toilet.

\section{Hospital environment}

Samples of the hospital environment consisted of medico-technical equipment (operating tables, table and tool boxes for the dressing, incubator), other equipment (patient beds) as well as air and surfaces.

\section{Description of the barriers in hospital hygiene}

Gaweye District Hospital in Niamey had no a decision-making body and promotion structures for hospital hygiene. Nevertheless, there was a health and sanitation service. No organization existed for the control of healthcare-associated infections.
Thus, the "structure" component is described as follows:

\section{Availability of management tools}

Given the fact that there is no Hospital Hygiene service, there are no hospital hygiene management tools. The available management documents are the national guide for management of waste from health care, the document on the written procedure for hand washing and disinfection-sterilization of equipment.

\section{Human resources}

There is a shortage of qualified personnel, especially concerning the maintenance staff, the majority of which is made of women who are volunteers without a financial incentive. The head of the hygiene and sanitation department is mainly responsible for waste management and food control visits around the hospital. For health care workers, we note the permanent passage of public health students (basic health workers, nurses, midwives, caregivers, medical students, etc.)

\section{Material resources}

There was a considerable insufficiency of equipment for the hospital hygiene. Protective equipment for maintenance workers was old and was hardly replaced. The amount of consumables (such as gloves) was insufficient. This means that patients were obliged to pay for the gloves so that they could be cared for. The permanent nonavailability of detergents and liquid soap led to poor dilution for biocleaning and hand hygiene. The surgery department had two dolls for the sterilization of equipment and instruments. The laundry room had a single machine used to wash clothes and outfits for the operating theater. For waste management, the hospital lacks different types of bins according to waste management standards. This means that: trash bags, coded trash cans, non-manual trash bins. The hospital's incinerator is not functional and the pungent wastes are burned in a pit dug for this purpose.

\section{Financial resources}

There was no budget line to finance hygiene-related expenses at the hospital level. 
However, there were funds called "delegated credit" which was not always available. It is a budget of 700000 FCFA which is intended for hygiene and office consumables. Expenses for hygiene products are made through a "commitment voucher" sent to the supplier and paid directly by the national treasury after delivery.

Concerning the management of cleaning-disinfection products and equipment, the Manager mentions that there is a lack of staff for these tasks. There is only one person responsible for hygiene who is the sanitation hygiene technician.

\section{Assessment of the quality of barriers and hospital hygiene}

The overall score of the hospital hygiene component was $8 / 32$ ie $25 \%$ (Table 1). Hand hygiene and asepsis-antisepsis at the Gaweye district hospital in Niamey was 3/10 (30\%) (Table 2). Through direct observation, waste management at Gaweye District Hospital in Niamey was assessed and scored $2 / 7(28.57 \%)$ across the variables shown in Table 3. Disinfection-sterilization score at the Gaweye District Hospital in Niamey was $10 / 15$ or $66.66 \%$ (Table 4 ). The biocleaning of the environment of Gaweye district hospital in Niamey was 3/11 (27.27\%).

Thus, the "process" component globally describes the barrier practice of hospital hygiene at the Gaweye district hospital in Niamey with a score of $18 / 43$ $(41.86 \%)$.

\section{Respect for the implementation of barriers in hospital hygiene}

Respecting the implementation of hospital hygiene barriers results from pooling adequate resources (available and accessible) in a process adapted to improve health. Thus, its score was $26 / 75(34.66 \%)$. It is obtained through the pooling of the scores of the components of the structure and the process.

\section{Contamination rate of the hospital environment.}

The contamination of the hospital environment, at Gaweye District Hospital in Niamey, was characterized by pathogenic germs. Staphylococcus aureus has been identified in all sampled soils (14/14), and absent in one bed (11/12 ratio) and the sterile tool box. Faecal colifors where found at 7 out of 12 beds and even at the operating table in the operating room and from the incubator to the nursery.

Salmonella spp was found at six out of 12 beds compared to 9 out of 14 soils sampled.

The bio contamination score of soils, equipment and medical technical equipment was $2 / 32$, ie a compliance percentage of $6.25 \%$. Air in the operating theater and recovery room at Gaweye District Hospital in Niamey was contaminated with bacteria and fungi. The score of the aero-biocontamination of the hospital environment was 0/13 (Table $5)$.

\section{Assessment of the quality of hospital hygiene}

The results component, obtained during this study, made it possible to assess the quality of hospital hygiene at Gaweye District Hospital in Niamey. Thus, the assessment scores of the main component are shown in Table 6.

The assessment of hospital hygiene quality score of Gaweye District Hospital in Niamey was $28 / 120$ ie $23.33 \%$. 
Table 1: Scores according to the different criteria of the structure component in hospital hygiene of the Gaweye district hospital of Niamey in 2018.

\begin{tabular}{llll}
\hline \multicolumn{1}{c}{ Sub-components } & Score obtained & Expected score \\
\hline Hospital hygiene service & 0 & 5 & \\
Human ressources & 1 & 3 & \\
Material resources & 2 & 5 & \\
Management Tools & 5 & 16 \\
Financial ressources & 0 & 3 \\
Structure & 8 & 32 \\
\hline
\end{tabular}

Table 2: Scores of the different aspects of the hand hygiene sub-component and asepsis-antisepsis at the Niamey Gaweye District Hospital in 2018.

\begin{tabular}{lll}
\hline Variables & Score obtained & Expected score \\
\hline Knowledge of hand hygiene & 0 & 1 \\
Simple washings & 0 & 1 \\
Antiseptic wash & 0 & 1 \\
Surgical wash & 0 & 1 \\
Hydro alcoholic friction & 0 & 1 \\
Wearing a blouse & 1 & 1 \\
Glove port & 1 & 1 \\
70 alcohol use for antisepsis. & 1 & 1 \\
Presence of handwashing devices in all hospital wards & 0 & 1 \\
Presence of handwashing device at all care rooms & 0 & 1 \\
Total score & 3 & 10 \\
\hline
\end{tabular}

Table 3: Scores of different aspects related to the management of waste from care at Gaweye district hospital in Niamey in 2018.

\begin{tabular}{lll}
\hline \multicolumn{1}{c}{ Variables } & Score obtained & Expected score \\
\hline Biomedical waste management & 0 & 1 \\
Respect of coding for garbage cans & 0 & 1 \\
traceability & 0 & 1 \\
Household waste treatment on site & 0 & 1 \\
Biomedical waste treatment (incineration or burn) & 1 & 1 \\
Hospital yard without household waste & 1 & 1 \\
Functional incinerator not overflowing & 0 & 1 \\
Total score & 2 & 7 \\
\hline
\end{tabular}


Table 4: Scores of various aspects related to disinfection and sterilization at Gaweye district hospital in Niamey in 2018.

\begin{tabular}{|c|c|c|c|}
\hline Variables & & Score obtained & Expected score \\
\hline Availability of sterilization equipment & 4 & 8 & \\
\hline $\begin{array}{l}\text { Existence of existing procedures and standards for } \\
\text { sterilization }\end{array}$ & 1 & 1 & \\
\hline $\begin{array}{l}\text { Transport of the closed-lid bucket containing the immersed } \\
\text { material to the sterilization room washbasin }\end{array}$ & 0 & 1 & \\
\hline $\begin{array}{l}\text { Is the duration of the immersion of the equipment from the } \\
\text { operating room to the sterilization room respected }(30 \mathrm{~min})\end{array}$ & 1 & 1 & \\
\hline $\begin{array}{l}\text { Rinse with sterile water or tap water before drying the } \\
\text { material }\end{array}$ & 1 & 1 & \\
\hline $\begin{array}{l}\text { Respect of the drying of the material (draining, wiping } \\
\text { with a sterile cloth)? }\end{array}$ & 1 & 1 & \\
\hline $\begin{array}{l}\text { Packaging of the material according to the sterilization } \\
\text { mode (Packaging in a sterile container: sachet, box ...) }\end{array}$ & 1 & 1 & \\
\hline Sterilization time according to the standards? & 1 & 1 & \\
\hline Total score & 10 & 15 & \\
\hline
\end{tabular}

Table 5: Distribution of germs identified at the level of equipment and medical technical equipment according to the services of Gaweye district hospital of Niamey in 2018.

\begin{tabular}{llll}
\hline Sample & Staphylococcus Aureus & Fecal coliform & Salmonella spp \\
\hline Surgery Service & & & \\
Operating table & + & + & + \\
Block (ground) & + & - & - \\
Table of the treatment room & + & + & + \\
Toolbox of the treatment room & - & - & - \\
Room1 (bed) & - & - & - \\
Room1 (ground) & + & - & + \\
Room2 (bed) & + & + & + \\
Room2 (ground) & + & - & + \\
Room3 (bed) & + & + & + \\
Room3 (ground) & + & + & + \\
Room4 (bed) & + & + & - \\
Room4 (ground) & + & + & + \\
Room5 (bed) & + & + & + \\
Room5 (ground) & + & - & + \\
Maternity Service & & & + \\
Incubator & + & + & + \\
Delivery Table1 & + & - & + \\
Delivery Table2 & + & - & - \\
Delivery room (ground) & + & - & + \\
Room1 (bed) & + & + & - \\
Room1 (ground) & + & - & - \\
Room2 (bed) & + & - & - \\
Room2 (ground) & + & - & \\
\hline
\end{tabular}




\begin{tabular}{lccc}
\hline Room3 (bed) & + & - & - \\
Room3 (ground) & + & + & + \\
Room4 (bed) & + & + & + \\
Room4 (ground) & + & - & + \\
Medicine Service & & & - \\
Room1 (bed) & + & - & + \\
Room1 (ground) & + & + & - \\
Room2 (bed) & + & - & + \\
Room2 (ground) & + & + & + \\
Room3 (bed) & + & + & + \\
Room3 (ground) & + & + & \\
\hline
\end{tabular}

+: Positive (presence) / -: Negative (absence)

Table 6: Assessments of Hospital Hygiene Quality at Gaweye District Hospital, Niamey, 2018.

\begin{tabular}{llll}
\hline Results & Components & Score obtained & Expected score \\
\hline Result 1 & Structure & 8 & 32 \\
& Process & 18 & 43 \\
Result2 & biocontamination & 2 & 32 \\
& aerobiocontamination & 0 & 13 \\
Total score & & 28 & 120 \\
\hline
\end{tabular}

\section{DISCUSSION}

The assessment of the hospital hygiene structure is related to the availability and effective accessibility of inputs in the hygiene process. Although a hospital hygiene service is inseparable from a health structure, we could note the absence of this structure at the Gaweye district hospital in Niamey. However, the hygiene and sanitation department tries to play this role which is difficult or impossible to fulfill. Several shortcomings have been noticed:

- The shortage of hospital hygiene management tools primarily expressed poor quality assurance in services, whether it is diagnostic or therapeutic, on the one hand, and the cleaning of the hospital environment, on the other hand;

- The inadequacy of human resources, in quantity and quality, constitutes a major handicap for the quality of care services and the cleanliness of the premises. This could be explained by the high number of volunteers among the maintenance staff. This situation could be confirmed by the need for recruitment issued by the workers and managers of the services surveyed;

- Insufficient material resources and especially the crucial lack of consumables for maintenance would expose all users to a huge infection risk because, even if the staff is qualified, the lack of means could give a poor quality of services. ;

- The insufficient financial resources devoted to hospital hygiene would include all others insufficiencies, showing plausibly the nonavailability of "inputs". During the interview, the manager and the hygiene and sanitation manager declared to have personally financed, repeatedly, the purchase of consumables like gloves and detergents.

The processes of implementation of the different barriers of hygiene make it possible to use the available and accessible "inputs" in order to reach objectives in an effective way. To evaluate the quality of hospital hygiene, compliance with the procedures for implementing the various barriers is necessary. Thus, in our study, the basic barriers taken into account are grouped together and discussed in two major processes (the process of hand hygiene and the process of the hospital environment).

Hand hygiene is a mandatory daily practice which is simple but critical. The compliance rate did not exceed $40 \%$, in most cases, even in controlled studies (John 2000). According to our survey, hand hygiene at 
Gaweye Hospital was 27.27\% compliance [score 3/11], "not enough" for minimal hand hygiene. This rate was significantly lower than the usual rate by Jhon (2000) and also compared to the results of Qasmi et al. (2018) which were $56.8 \%$ compliance.

Poor hand hygiene is a source of enormous health problems for patients. It is therefore a transmission factor of germs and the occurrence of IAS. In our study, 13/24 patients did not wash their hands before going to the toilet and 14/24 did not wash after the toilet. This would expose the hospital environment to a risk of coliform contamination.

The waste management score of Gaweye District Hospital in Niamey, following our observation, was 2/7 (28.57\%), which was well below the $60 \%$ of our evaluation grid. This difference indicated an insufficient quality of waste management. This could be explained by the fact that the financial resources allocated to waste management are generally almost nonentity at 85.25\% (Public Health and Health Education Directorate 2015).

The deficiencies observed at Gaweye District Hospital in Niamey were similar to those observed in Klouékanmè-Toviklin-Lalo health zone where there was an insufficient availability of equipment at the production site, insufficient execution of collection, transportation and treatment of biomedical waste (Saizonou et al., 2014). In fact, in all regions of Niger, it is the municipalities that are most often involved in the removal of biomedical waste. This was, indeed, the case of Gaweye district hospital according to the interview we had the head of hygiene and sanitation.

Every hospital must have its own sterilization devices for the prevention of infections. Sterilization is not absolute; it consists in obtaining a reduction in the number of germs. This justifies the importance of pre-cleaning before sterilization. In fact, evaluation of sterilization at the Gaweye district hospital in Niamey gave a score of $10 / 15$ ie $66.66 \%$ belonging to the interval of $[60 \%-80 \%$ [of the Verkvisser scale which qualifies this rate as "average quality". Thus, sterilization has the best quality of all hospital hygiene barriers at Gaweye district hospital in Niamey.
Environment, a potential source of nosocomial infections, helps greatly to control nosocomial infections.

The contamination of the hospital environment is mainly characterized by the interaction between two factors: the biocontamination of surfaces and the aerobiocontamination. This interaction is ensured in the environment by the sedimentation of the germs of the air towards the horizontal surfaces of the room, floor, tables, seats, bedding or instruments.

Aerobiocontamination at the Gaweye District Hospital was high (averaging nearly $10,000 \mathrm{CFU} / \mathrm{m} 3)$. This contamination concerned all the services in hospital including the operating theater. It can be explained by several factors among which the architecture of the premises, the quality of the biocleaning, etc; thus, the level of contamination varies according to the type of premises considered (Keirsbulck 2006, Barbadoro 2016, Huart 2011). Indeed, the aerobiocontamination and the biocontamination of the contact surfaces have a very strong link. In the case of our study, this could be explained by the presence of bacteria (bioaerosols) in the ambient air and the contamination of the supports (hypothesis of correlation between the two aspects). This hypothesis is better understood through the work of Beggs et al. (2014) and Birgand et al. (2015).

The link between the biocontamination of the air and the contact supports is highly maintained and determined by the quality of the biocleaning and disinfection. At the Gaweye district hospital in Niamey, the biocleaning was done with only detergents that are difficult to provide by officials (sometimes provided by their agents funds). This low level of cleanliness was confirmed by the presence of Staphylococcus aureus in all contact media analyzed (Beggs et al., 2014, Dallolio et al., 2017, Smith et al., 2018, Agodi et al.,2015, Fauci et al., 2017).

The role of contaminated air has been established in the contamination of surgical wounds. The study of Napoli et al. (2012) has revealed that air sampling system near the surgical wound may be the best way to identify the risk of exposure to pathogens and to develop measures of infection for 
operations presenting a high risk of contamination.

Biocleaning, in addition to its involvement in determining the aerobiocontamination, could also be a factor for the resistant to Methicillin Staphylococcus aureus (RMSA) at Gaweye hospital because all the surfaces of contact (Soils, beds) were infected by the Staphylococcus aureus; whether they have been cleaned or not. These hypotheses can be confirmed by the biocleaning score of our assessment, which was $3 / 10$ or $30 \%$ and considered "insufficient quality". The quality of hospital hygiene was determined through the analysis of the three components (Structure, process, result).

Regarding the structure, its evaluation gave a poor quality through the score $8 / 32$ $(25 \%<60 \%)$.

This would be explained by the lack of a proper hospital hygiene service, lack of management tools for hospital hygiene, lack of qualified personnel, lack of financial resources, and so on.

For the process, hand hygiene and asepsis-antisepsis were observed which were of average quality $(27.27 \%$ [3/11] less than $60 \%$ ). The study of Ouendo et al, (2015) reported that the staff training and the availability of the intrants reinforce the quality of the hygiene of the hands what is not the case in presented the study. For biocleaning, the survey gave an "inadequate quality" with a proportion of $3 / 10(30 \%)$. These results are confirmed by the identification of Staphylococcus aureus at all level of the hospital environment, by the presence of coliform and salmonella spp at the majority of these contact materials and aerobiocontamination.

The quality of hospital hygiene at the Gaweye District Hospital in Niamey is established by the conclusion of the "results" component at the end of the "structureprocess" operation: defective hand hygiene, poor waste management, insufficient cleaning of surfaces and premises.

All these shortcomings are logically related to the final score of the main component which was $28 / 120$ ie $23.33 \%$. Thus, according to the Varkevisser evaluation grid, the quality of hospital hygiene at Gaweye district hospital in Niamey is "insufficient". This would expose users of Gaweye Hospital to nosocomial infections and healthcare-associated infections.

\section{Conclusion}

This inestigation conducted at Gaweye District Hospital in Niamey revealed inadequate quality of hospital hygiene. It involves huge gaps in the implementation of hospital hygiene barriers ("Structure-processresult"), which can generate proven risks of nosocomial infections and poor quality of care and services at Gaweye District Hospital in Niamey. This reality has confirmed our study hypothesis which was: "Respecting the practice of hospital hygiene barriers would improve the quality of care at the Gaweye district hospital in Niamey ". Indeed, the bad conditions, of the implementation of hospital hygiene barriers, the non-availability of infection prevention management tools associated with care and their monitoring, make it difficult to assess and establish prevalence of IAS at the Gaweye District Hospital in Niamey. It is important to set up an adequate hospital hygiene service at the Gaweye district hospital and especially to support it financially. Thus, an assessment of the prevalence of HAIs is a future avenue of research in this hospital because IAS is still much underestimated in the health structures in Niger.

\section{COMPETING INTERETS}

The authors of the present article state that there is no conflict of interest concerning its publication.

\section{AUTHORS' CONTRIBUTIONS}

DCC was the lead investigator and participated in the planning and execution of the study, performed the data entry and analysis and was the lead author responsible. SG and OEM participated in the planning of the study and contributed to the drafting process. YSM and AHM participated in data capture and analysis and contributed to the writing process. All authors read and approved the final manuscript.

\section{AKNOWLEDGEMENTS}

We thank the West African Health Organization (WAHO) for funding this research work and the authorities of the 
Gaweye District Hospital in Niamey for allowing us the conduct the study in their centre.

\section{REFERENCES}

Agodi A, Auxilia F, Barchitta M, Cristina ML, D'Alessandro D, Mura I, Nobile M, Pasquarella C, on behalf Italian Study Group of Hospital Hygiene. 2015. Operating theatre ventilation systems and microbial air contamination in total joint replacement surgery: results of the GISIO-ISChIA study. J. Hosp. Infect., 90: 213-219. DOI: 10.1016/j.jhin.2015.02.014.

Ahoyo TA, Bankolé HS, Adéoti FM, Gbohoun AA, Assavèdo S, AmoussouGuénou M, Kindé-Gazard DA, Pittet D. 2014. Prevalence of nosocomial infections and anti-infective therapy in Benin: results of the first nationwide survey in 2012. Antimicrob. Resist. Infect. Control., 3:17. DOI: 10.1186/2047-2994-3-17

Barbadoro P, Bruschi R, Martini E, Savini S, Gioia MG, Stoico R, Di Tondo E, D'Errico MM, Prospero E. 2016. Impact of laminar air flow on operating room contamination, and surgical wound infection rates in clean and contaminated surgery. Eur. J. Surg. Oncol. EJSO., 42: 1756-1758.

DOI:

10.1016/j.ejso.2016.06.409.

Beggs C, Knibbs LD, Johnson GR, Morawska L. 2015. Environmental contamination and hospital-acquired infection: factors that are easily overlooked. Indoor Air., 25: 462-474. DOI: 10.1111/ina.12170.

Birgand G, Toupet G, Rukly S, Antoniotti G, Deschamps M-N, Lepelletier D, Pornet C, Stern JB, Vandamme YM, van der Mee-Marquet N, Timsit JF, Lucet JC. 2015. Air contamination for predicting wound contamination in clean surgery: A large multicenter study. Am. J. Infect. Control., 43: 516-521. DOI: 10.1016/j.ajic.2015.01.026

Dallolio L, Raggi A, Sanna T, Mazzetti M, Orsi A, Zanni A, Patrizia Farruggia, Erica L. 2017. Surveillance of Environmental and Procedural Measures of Infection Control in the Operating Theatre Setting. Int. J. Environ. Res.
Public. Health., 15: 46. DOI: https://doi.org/10.3390/ijerph15010046

Dégbey C, Aguèmon B, Ouendo E-M, Makoutodé M, Simon A. 2013. Etude de la qualité du matériel médico-technique utilisé dans les blocs opératoires en vue de la prévention des infections associées aux soins et services au Centre National Hospitalier et universitaire de Cotonou au Bénin. J. Société Biol. Clin. Bénin., 018: 29-35.

Djibo H, Kamay M, Baden A. 2013. P254: The hospital-acquired infections in regional hospital in Niger Tahoua. Antimicrob. Resist. Infect. Control., 2(S1):254. DOI: https://doi.org/10.1186/2047-2994-2-S1P254

Geberemariyam BS, Donka GM, Wordofa B. 2018. Assessment of knowledge and practices of healthcare workers towards infection prevention and associated factors in healthcare facilities of West Arsi District, Southeast Ethiopia: a facility-based cross-sectional study. Arch Public Health., 76:69. https://doi.org/10.1186/s13690-0180314-0.

Huart C. 2011. Air treatment in a hospital environment. Place of mobile units: experience in pediatric oncology at $\mathrm{CHU}$ Poitiers, Poitiers.

Iliyasu G, Dayyab FM, Habib ZG, Tiamiyu AB, Abubakar S, Mijinyawa MS, Habib AG.2016. Knowledge and practices of infection control among healthcare workers in a Tertiary Referral Center in North-Western Nigeria. Ann. Afr. Med., 15(1): 34-40. DOI: $10.4103 / 1596-$ 3519.161724 .

John M. 2000. Washing and disinfecting hands. J. Can. Dent. Assoc., 66: 546-7.

Keirsbulck M. 2006. Quality and indoor air treatment in hospitals: what are the physicochemical risks?Application to the Lenval pediatric hospital in Nice. https://documentation.ehesp.fr/memoires /2006/igs/keirsbulck.pdf

La Fauci V, Genovese C, Facciolà A, Palamara MAR, Squeri R. 2017. Fiveyear microbiological monitoring of wards and operating theatres in southern Italy. J. Prev. Med. Hyg., 58: E166E172. 
Mehinto DK, Vignon KC, Biaou G. Amossou FL, Ezin ESM, Natta'ntcha NH. 2014. Les infections du site opératoire (ISO) dans les cliniques universitaires de chirurgie viscérale (CUCV) " "A" » et " "B" » du Centre National Hospitalier et Universitaire Hubert Koutoucou Maga (CNHU-HKM) de Cotonou: aspects épidémiologiques, diagnostiques et thérapeutiques. J. Afr. Chir. Dig., 14(2): 1736-44.

Napoli C, Tafuri S, Montenegro L, Cassano M, Notarnicola A, Lattarulo S, Lattarulo S, Montagna MT, Moretti B. 2012. Air sampling methods to evaluate microbial contamination in operating theatres: results of a comparative study in an orthopaedics department. J. Hosp. Infect., 80: 128-32. DOI: 10.1016/j.jhin.2011.10.011.

Nejad SB, Allegranzi B, Syed S, Ellis B, Pittet D. 2011. Health-care-associated infection in Africa: a systematic review. Bull. World Health Organ., 89 (10): 757-65. DOI: 10.2471/BLT.11.088179.

Nouetchognou JS, Ateudjieu J, Jemea B, Mesumbe EN, Mbanya D. 2016 Surveillance of nosocomial infections in the Yaounde University Teaching Hospital, Cameroon. BMC Res. Notes., 9(1): 505. DOI: 10.1186/s13104-0162310-1

Qasmi SA, Mahmood Shah SM, Wakil HYI, Pirzada S. 2018. Guiding hand hygiene interventions among future healthcare workers: implications of knowledge, attitudes, and social influences. Am. J. Infect. Control., 46(9): 1026-1031. DOI: 10.1016/j.ajic.2018.02.019

Saizonou J, Ouendo EM, Agueh V, Tokplonou E, Makoutodé M. 2014. Évaluation de la qualite de la gestion des dechets biomedicaux solides dans la zone sanitaire Klouekanme-ToviklinLalo au Bénin Evaluation of the management quality of solid waste in the biomedical Klouékanmè-Toviklin-Lalo health zone in Benin. J. Int. Santé Trav., 1: $1-11$. http://www.journalsantetravail.net/jist/ca hiers/cahier20141/1Saizonou.pdf

Smith J, Adams CE, King MF, Noakes CJ, Robertson C, Dancer SJ. 2018. Is there an association between airborne and surface microbes in the critical care environment? J. Hosp. Infect., 100(3): e123-e129.

DOI: 10.1016/j.jhin.2018.04.003.

Ouendo EM, Saizonou J, Degbey C, Glele Kakai C, Glele T, Makoutode M. 2015. Gestion du risque infectieux associé aux soins et services au Centre National Hospitalier et Universitaire Hubert Koutoukou Maga de Cotonou (Bénin). Int. J. Biol. Chem. Sci., 9(1): 292-300.

Varkevisser CM, Pathmanathan I, Brownlee A. 1993. Development and Implementation of Health Systems Research Programs: Part I, Formulation and Testing of a Proposal. IDRC, Ottawa.

WHO Patient Safety and World Health Organization. 2005. Dept. of Health System Policies and Operations. Global Challenge for Patient Safety, 2005-2006: Clean Care is Safer Care / Global Alliance for Patient Safety. WHO. http://apps.who.int/iris/bitstream/handle/ 10665/43374/9242593737_eng.pdf?

Zhou Y, Zhang D, Chen Y, Zhou S, Pan S, Huang Y, Ba-Thein W. 2014. Healthcare-Associated Infections and Shanghai Clinicians: A Multicenter Cross-Sectional Study. PLoS ONE., 9(8): e105838.

DOI: 